\title{
Estado de conhecimento e questões do campo científico
}

\author{
State of knowledge and issues of the scientific field
}

Marilia Costa Morosini*

Pontifícia Universidade Católica do Rio Grande do Sul

Resumo Este texto objetiva desvelar questões sobre a construção de Estados de Conhecimento na área da Educação e apontar posições teóricas fundamentadoras dessas questões com vista à prática de pesquisa articulada à realidade nacional. Parte de tematizações encima de experiências, ao longo de quatro anos, em um curso de pós-graduação de excelência. Identifica categorias de análise na perspectiva do campo científico (Bourdieu): Politicas públicas do Estado-nação e da área disciplinar; Finalidades do Estado de Conhecimento para a ruptura de pré-conceitos (Quivy e Capenhoudt); Qualidade interna do Estado de Conhecimento (Lovitts) marcado pela originalidade; e Metodologia de aprendizagem colaborativa. Conclui pela complexidade da produção de um Estado de Conhecimento decorrente das inúmeras inter-relações sócio-científicas e resgata sua importância para a inserção no campo científico e na área do objeto de pesquisa.

PALAVRAS-CHAVE: Educação superior, Campo científico, Estado de conhecimento.

Abstract This article aims to uncover questions about the construction of the State of Knowledge in Education and point out basic theoretical positions of these issues with a view to research practice articulated the national reality. It departs fromthematizations over four years experiences in a course of postgraduate excellence. The article identifies categories of analysis from the perspective of scientific field (Bourdieu): Public policies of the nation-state and disciplinary area; Purposes of the Stateof Knowledge to break pre-conceptions (Quivy and Capenhoudt); Internal quality of the State Knowledge (Lovitts) marked by originality; Methodology of collaborative learning. It concludes with the complexity of state of knowledge production resulting from numerous socio-scientific interrelations and rescues its importance for the inclusion in the scientific field and the object of the research.

KEYWORDS: Higher Education, Scientific field, State of knowledge. 


\title{
Introdução
}

A concepção de produção científica é bastante complexa e congrega relações interdisciplinares de conhecimento. Stoleroff e Patrício (1995), buscando clarear esta complexidade, identificam como componentes do trabalho científico: leitura e reflexão; elaboração e coordenação de projetos; realização de investigação; e redação de artigos, relatórios e livros científicos. No meu entendimento, estado de conhecimento é identificação, registro, categorização que levem à reflexão e síntese sobre a produção científica de uma determinada área, em um determinado espaço de tempo, congregando periódicos, teses, dissertações e livros sobre uma temática específica.

Nesta reflexão, faz-se necessário considerar que a construção de uma produção cientifica está relacionada não só à pessoa/pesquisador que a produz, mas a influências da instituição na qual está inserida, do país em que vive e de suas relações com a perspectiva global. Em outras palavras, a produção está inserida no campo científico e, consequentemente, em suas regras constitutivas, segundo as quais o

universo "puro" da mais "pura" ciência é um campo social como outro qualquer, com suas relações de força e monopólios, suas lutas e estratégias, seus interesses e lucros, mas onde todas essas invariantes se revestem de formas específicas. (BOURDIEU, 1983, p. 122, grifos do original).

No Brasil, a consolidação da produção científica sobre Educação é ainda incipiente, identificando-se um crescente esforço desta área na construção de estados de conhecimento. A produção segue orientações e avaliações definidas prioritariamente pela área disciplinar. Este fato se solidifica com a centralização estatal da educação superior no Brasil através de determinações do Sistema Nacional de Educação/Sistema Nacional de Pós-Graduação (SNE/SNPG) e do Sistema Nacional de Ciência, Tecnologia e Inovação (SNCT\&I), cujas gestões têm como principais atores a Coordenação de Aperfeiçoamento de Pessoal de Nível Superior do Ministério da Educação (Capes/ MEC) e o Conselho Nacional de Desenvolvimento Científico e Tecnológico do Ministério da Ciência, Tecnologia e Inovação (CNPq/MCTI).

Este campo científico, do qual a produção é resultante, é, aparentemente, bem estruturado. Eivado por tensões, é o lugar de uma

\begin{abstract}
luta, mais ou menos desigual, [...] segundo a estrutura da distribuição do capital no campo (grau de homogeneidade), os dominantes, ocupando as posições mais altas na estrutura de distribuição de capital científico, e os dominados, isto é, os novatos, que possuem um capital científico tanto mais importante quanto maior a importância dos recursos científicos acumulados no campo. (BOURDIEU, 1983, p. 136-137, grifos do original).
\end{abstract}

Nesta perspectiva, a consulta, a sistematização e a análise do que foi produzido no seu campo disciplinar, em especial no país do pesquisador, são importantes para fundamentar o que será produzido numa tese ou dissertação qualificada. Sem dúvida, o estado do conhecimento se constitui numa importante fonte para a produ- 
ção, não só por acompanhar todo o processo monográfico, mas prioritariamente, por contribuir para a ruptura com os pré-conceitos (QUIVY, CAMPENHOUDT, 2005) que o pesquisador porta ao iniciar o seu estudo. Este procedimento é proposto em um cenário marcado pela não consolidação da produção da área da Educação no Brasil, pela forte influência de órgãos governamentais na condução da avaliação da produção científica e pelas decorrentes questões políticas e sociais que direcionam esta produção (MOROSINI, 2012).

O texto objetiva desvelar questões substantivas da discussão contemporânea sobre a construção de uma produção científica, de forma geral, e, em especifico, de Estados de Conhecimento da área da Educação; e apontar posições teóricas fundamentadoras de questões substantivas com visa à prática de pesquisa articulada à realidade nacional. Para dar conta da complexidade do tema e retratá-lo em profundidade, a metodologia utilizada é de caráter qualitativo com traços identificadores de um estudo de caso, envolvendo teóricos basilares, documentos oficiais e análise de experiência educacional no período de 2010 a 2013. Este corpus teórico-empírico de análise se interpolam em vários momentos, sugerindo apenas um movimento constante no confronto teoria-empiria (LÜDKE, ANDRÉ, 1986, p. 23).

Para dar conta destes objetivos, o texto identifica categorias de análise na perspectiva do campo científico (Bourdieu) apoiada na compreensão da sociedade e da área de conhecimento da educação. São apontadas: questões estado-nação - identificando condicionantes desta produção da ciência oficial - orientações da área de Educação sobre avaliação da produção científica no tocante a livros, coletâneas e periódicos; questões sobre as finalidades - para a ruptura de pré-conceitos; questões de qualidade interna, marcada pela originalidade do tema, metodologia e/ou abordagem teórica; e questões de metodologia da prática via aprendizagem ativa/colaborativa.

\section{Questões Estado-Nação: políticas públicas e produção científica}

A produção científica tem entre suas temáticas, no patamar do Estado-nação, as políticas públicas. Bourdieu nos ensina:

Aqueles que estão à frente das grandes burocracias científicas só poderão impor sua vitória como sendo uma vitória da ciência se forem capazes de impor uma definição de ciência que suponha que a boa maneira de fazer ciência implica a utilização de serviços de uma grande burocracia científica, provida de créditos, de equipamentos técnicos poderosos, de uma mão-de-obra abundante. (1983, p. 124).

A constatação de Bourdieu é uma concepção vigente na ciência contemporânea, mesmo em contextos emergentes que apontam para uma transição paradigmática. Da mesma forma, a relação entre área disciplinar e produção científica é muito complexa. É composta por estratos de diferentes níveis e posturas ideológicas. A definição oficial de ciência é defendida e se constitui em um conjunto de recursos científicos herdados do passado que existem em estado objetivado (instrumentos, obras, instituições, etc.) e em estado incorporado (habitus científicos, sistemas de ensino). No 
caso do Brasil, existe uma tensão entre a área de Educação e as outras áreas de conhecimento da mesma forma que dentro da própria área. É neste jogo que as diferentes posições buscam defender sua concepção de ciência, com estratégias e critérios que as fortificam. E inculcam

[...] sistematicamente habitus científicos ao conjunto dos destinatários legítimos da ação pedagógica, em particular a todos os novatos do campo da produção propriamente dito. Além das instâncias especificamente encarregadas da consagração (academias, prêmios, etc.), ele compreende ainda as revistas científicas que, pela seleção que operam em função de critérios dominantes, consagram produções conformes aos princípios da ciência oficial,... (BOURDIEU, 1983, p. 138).

No Brasil, a educação superior é centralizada no governo central e a produção é gestada e avaliada com a coordenação da Capes, num sistema que integra a comunidade científica da área, que cria e acompanha todo o processo. Em análise do documento geral da área de Educação, nas "Considerações gerais sobre o estágio atual da Área” para o triênio 2010-2012, é detectado um crescimento significativo da produção. Essa produção está, em sua maioria, veiculada em livros (na forma de obra integral ou coletâneas), o que é característico da área também em âmbito internacional (JAVER, USHER, MCELROY, 2012).

Ressalte-se, no entanto, que a produção em periódicos científicos nacionais ampliou-se mais de 3 vezes nos últimos dez anos,.... No que tange à produção publicada fora do país, embora ainda concentrada em Programas mais consolidados, tem crescido quantitativamente, assim como se direcionado a periódicos de maior reputação internacional na Área. (CAPES, 2013, p. 5).

A Capes utiliza um conjunto de procedimentos para a estratificação da qualidade da produção intelectual dos programas de pós-graduação. Tal processo foi concebido para atender às necessidades específicas do sistema de avaliação e é baseado no aplicativo Coleta de Dados, preenchido pelos programas de pós-graduação. A partir de 2014, a CAPES instituiu a plataforma Sucupira. A avaliação é realizada pelas áreas de conhecimento. Como resultado, disponibiliza uma lista com a classificação dos veículos de publicação científica utilizados pelos pesquisadores dos programas de pós-graduação. Há avaliação de periódicos, livros e coletâneas e, secundariamente, de eventos.

A classificação Qualis de periódicos enquadra estes veículos em estratos indicativos da qualidade: A1, o mais elevado; A2; B1; B2; B3; B4; B5; C - com peso zero. Os fatores que influem na classificação do periódico são: reconhecimento na área; ISSN $^{1}$; coordenação; caráter acadêmico-científico; atendimento a normas editoriais; amplitude de circulação; periodicidade e regularidade; atendimento a prazos; diversidade nacional e institucional do conselho editorial e corpo de pareceristas; número de artigos por ano; diversidade institucional dos autores publicados; indexação em bases de dados nacionais e internacionais. 
$\mathrm{Na}$ avaliação do triênio 2010-2012, foram classificados 1721 periódicos, a grande maioria no estrato $\mathrm{B}$. Destes, $5,2 \%$ foram alocados na categoria A1; 7,7\% na $\mathrm{A} 2 ; 12,5 \%$ na B1; $13,8 \%$ na B2; $17,2 \%$ na B3; $21,5 \%$ na B4; e $22,1 \%$ na B5. No estrato C, contabilizaram-se 855 periódicos (CAPES, 2013).

A classificação Qualis de livros, no triênio anterior, teve um roteiro aprovado pela Capes, integrado por conceitos e definições comuns e sugestão de modelo de ficha de classificação, servindo como orientação para as 23 áreas de conhecimento integrantes deste órgão. As publicações avaliadas segundo este roteiro são divididas entre obras integrais e coletâneas ou dicionários, divididos em quatro estratos: L4, L3, L2 e L1. A classificação L4 é a maior e L1, a menor, tanto para livros como para coletâneas e dicionários. Para ser classificada, a obra deve possuir ficha catalográfica, com ISBN ${ }^{2}$, mínimo de 50 páginas e ser decorrente de pesquisa de professores da pós-graduação (CAPES, 2013).

Dicionários e coletâneas são avaliados conforme a articulação entre os textos contidos e os critérios de relevância, caráter inovador e potencial de impacto. Também são levados em conta aspectos técnicos, como a qualidade da edição e a distribuição/circulação. São atributos que valorizam a obra: participação discente; presença de autores e organizadores estrangeiros; apoio de agência para publicação; expressão de pesquisa financiada; conexão com convênios e redes nacionais ou internacionais; e prêmios.

Destaca-se a presença dos critérios qualitativos na avaliação da produção, em especial relevância, inovação e potencialidade de impacto. A relevância é compreendida como contribuição para o desenvolvimento científico-tecnológico da área de conhecimento, bem como para a resolução de problemas nacionais relevantes, considerando a atualidade da temática. Além disso, questões formais como clareza e objetividade do conteúdo, rigor científico, precisão de conceitos, terminologia e informações, senso crítico, bibliografia consistente e qualidade das ilustrações, linguagem e estilo são consideradas. A inovação é marcada pela originalidade na formulação do problema de pesquisa e/ou nos métodos adotados. Já a potencialidade de impacto engloba circulação e distribuição previstas, língua, reimpressão ou reedição e possíveis usos no meio acadêmico e fora dele.

O material advindo de congressos é usado secundariamente na avaliação da produção da área. Esse corpus pode ser classificado em: grandes conferências, que objetivam abordar o tema central do evento, que deve perpassar todos os eixos; trabalhos de oferta, que representam aquilo que a comunidade da área está produzindo; e trabalhos encomendados pelos grupos de trabalho (GTs), com o objetivo de complementar uma lacuna teórica ou metodológica da área e/ou a introdução de um novo tema. Os trabalhos encomendados podem responder aos objetivos de mais de um grupo de trabalho, identificando uma perspectiva de interdisciplinaridade. 


\section{Questões das Finalidades do Estado de Conhecimento: a ruptura de pré-conceitos}

Uma segunda categoria temática acerca do Estado de Conhecimento se refere às finalidades do mesmo. Parte-se da crença que o fato científico é conquistado, construído e verificado (BACHELARD, 1985), ou seja: conquistado sobre os preconceitos; construído pela razão; e verificado nos fatos. O indivíduo, quando inicia um trabalho científico, está minado de crenças e de saberes sobre o tema que escolheu investigar. E, para que ocorra a transformação do fato social em científico, há que se buscar um afastamento deste cotidiano. A isto se denomina o processo de ruptura com os seus pré-conceitos (Figura 1).

A ruptura consiste precisamente em romper com os preconceitos e as falsas evidencias, que somente nos dão a ilusão de compreender as coisas. A ruptura é, portanto, o primeiro acto constitutivo do procedimento científico. (QUIVY, CAMPENHOUDT, 2005. p. 25)

Num segundo momento do processo de investigação, o pesquisador, após a quebra de pré-conceitos, realiza a construção de seu modelo de análise e, posteriormente, passa à verificação do mesmo.

Figura 1: $O$ processo de ruptura no trabalho científico

Fonte: Quivy, Campenhoudt, 2005.

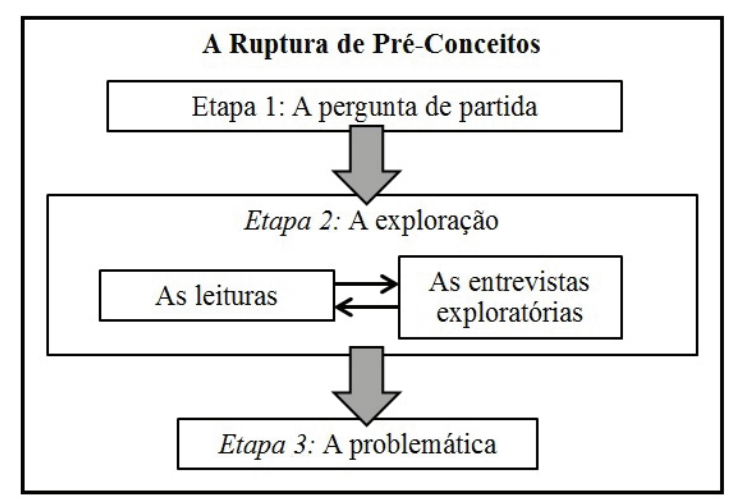

Quando falamos em quebra de preconceitos, não significa dizer que a pesquisa não tem viés ideológico. Autores consagrados da área das ciências sociais (ALBARELLO ET AL., 2005) reconhecem tal fato. Desde a escolha do objeto até a forma de compreendê-lo, o pesquisador está eivado de posições sobre a temática. Com a fase da ruptura, busca-se minimizar os pré-conceitos, e a metodologia é fator imprescindível.

A ruptura tem diversas etapas: a etapa que aqui mais se relaciona ao escopo deste texto é a exploração, que se apoia na prospecção do campo de nossa produção, através, basicamente, de leituras e de entrevistas exploratórias. 
A Leitura - Tratar-se-á, concretizando, de selecionar muito cuidadosamente um pequeno número de leituras e de se organizar para delas retirar o máximo de proveito, o que implica um método de trabalho correctamente elaborado. É, portanto, um método de organização, de realização e de tratamento das leituras .... Este é indicado para qualquer tipo de trabalho, seja qual for o seu nível. (p. 49)

O autor recomenda que utilizemos alguns princípios básicos para a escolha do corpus de análise (p. 50 - 51). São eles: Começar pela pergunta de partida; evitar sobrecarregar o programa, selecionando as leituras. É preferível ler de modo aprofundado e crítico alguns textos bem escolhidos a ler superficialmente milhares de páginas; Procurar, na medida do possível, documentos cujos autores não se limitam a apresentar dados, mas incluam também elementos de análise e de interpretação; ter o cuidado de recolher textos que apresentem abordagens diversificadas do fenômeno estudado; Oferecer-se, a intervalos regulares, períodos de tempo consagrados à reflexão pessoal e às trocas de pontos de vista com colegas ou com pessoas experientes.

De acordo com Quivy e Campenhoudt, "as operações de leituras visam essencialmente assegurar a qualidade da problematização, ao passo que as entrevistas e os métodos complementares ajudam especialmente o investigador a ter um contacto com a realidade vivida pelos actores sociais" $(2005$, p. 49).

Pela leitura, além de revermos os apoios teóricos que fundamentam nossa temática, buscamos identificar o que já foi produzido em matéria de pesquisa sobre a mesma. É importante que se estabeleçam critérios quanto ao recorte de tempo a ser examinado, baseado em fatos e/ou marcos regulatórios que possam ter afetado a temática além da própria evolução temporal (CAMPENHOUDT, 2003). Em geral, muitos aprendizes, quando começam a buscar material para fundamentar o seu estudo, têm a noção que não há nada ou quase nada sobre o seu tema: "esta opinião resulta, em regra, de uma má informação. Todo o trabalho de investigação se inscreve num continuum e pode ser situado dentro de, ou em relação a, correntes que o precedem e influenciam" (QUIVY, CAMPENHOUDT, 2005, p. 50). Afirmam ainda que "é, portanto, normal que um investigador tome conhecimento dos trabalhos anteriores que se debruçam sobre objectos comparáveis e que explicite o que aproxima ou distingue o seu trabalho destas correntes de pensamento" (QUIVY, CAMPENHOUDT, 2005, p. 50). Os autores denominam de validade externa o processo de situar o tema em relação a quadros conceituais reconhecidos. Esta contextualização, segundo os autores, é complementada por entrevistas com profissionais que conhecem a temática e/ou professores experts no tema em pesquisa.

\section{Questões de Qualidade Interna do Estado de Conhecimen- to}

Uma terceira categoria temática acerca dos estudos sobre Estado de Conhecimento é a Qualidade Interna do mesmo. Apesar da existência de princípios e formatos diversos de produção científica, principalmente no caso de produção de dissertações e teses, resultantes de cursos de pós-graduação stricto sensu, Lovitts (2007), em Making the implicit explicit: creating perfomance expectations for the dissertation ${ }^{3}$, destaca 
qualidades universais de uma tese e de seus componentes. A principal característica é a natureza de uma contribuição original, marcada pela identificação do novo, seja ele teórico, metodológico e/ou empírico. Acresce às qualidades da produção: "ir do não trivial para um avanço muito importante no nível empírico, conceitual, teórico ou político; ser útil e ter impacto; ser publicável nas mais reputadas revistas da área; ser do interesse do público interno e possivelmente do externo à comunidade em que foi produzida, provocando uma forma diferente de ver as coisas; ter influência na conversação e nas pessoas, na pesquisa e no ensino; ter implicações no desenvolvimento do campo, da disciplina, em outras disciplinas e/ou na sociedade"(LOVITTS, 2007, p. 34).

No caso específico da revisão de literatura, considerada como um dos principais componentes da produção, a autora apresenta (Quadro 1) os critérios analíticos para avaliar a revisão de literatura na perspectiva de seleção e tratamento do corpus de análise, ou seja, a abrangência do produzido e a síntese realizada pelo autor. No primeiro quesito, a razão definidora é a existência de critérios justificados para a seleção. No segundo, as referências para avaliação são: o que é estudado e o que precisa ser estudado na área; contextualização do tema na literatura como um todo e na história do campo; apreensão e aprimoramento dos conceitos sobre o tema; articulação de variáveis importantes e fenômenos relevantes para o tema; e apresenta síntese e domínio de uma nova perspectiva.

Os níveis de avaliação se estendem de 1 a 3 , sendo três o maior e melhor nível de revisão de literatura. A avaliação da revisão de literatura de uma tese, segundo abrangência e síntese, encontra-se detalhada no Quadro 1. 
Quadro 1: Avaliação da revisão de literatura de uma tese segundo abrangência e síntese.

Fonte: LOVITTS, 2007

\begin{tabular}{|c|c|c|c|c|}
\hline Categoria & Critério & 1 & 2 & 3 \\
\hline Abrangência & $\begin{array}{l}\text { Critérios } \\
\text { justificados } \\
\text { de inclusão e } \\
\text { exclusão da } \\
\text { revisão }\end{array}$ & $\begin{array}{l}\text { Não discute } \\
\text { os critérios } \\
\text { de inclusão e } \\
\text { exclusão }\end{array}$ & $\begin{array}{l}\text { Discute os } \\
\text { critérios de } \\
\text { inclusão e } \\
\text { exclusão }\end{array}$ & $\begin{array}{l}\text { Justifica a } \\
\text { inclusão e a } \\
\text { exclusão de } \\
\text { literatura }\end{array}$ \\
\hline \multirow[t]{6}{*}{ Síntese } & $\begin{array}{l}\text { Distingue o que } \\
\text { tem sido feito } \\
\text { na área do que } \\
\text { precisa ser feito }\end{array}$ & $\begin{array}{l}\text { Não distingue o } \\
\text { que foi realizado } \\
\text { e o que não foi }\end{array}$ & $\begin{array}{l}\text { Discute o que } \\
\text { tem sido e não } \\
\text { feito }\end{array}$ & $\begin{array}{l}\text { Examina } \\
\text { criticamente } \\
\text { o estado do } \\
\text { campo }\end{array}$ \\
\hline & $\begin{array}{l}\text { Situa o tema ou } \\
\text { problema na lite- } \\
\text { ratura acadêmica } \\
\text { como um todo }\end{array}$ & $\begin{array}{l}\text { Não situa o } \\
\text { tópico em } \\
\text { relação à } \\
\text { literatura } \\
\text { acadêmica como } \\
\text { um todo }\end{array}$ & $\begin{array}{l}\text { Alguma discus- } \\
\text { são da literatura } \\
\text { acadêmica como } \\
\text { um todo }\end{array}$ & $\begin{array}{l}\text { Situa clara- } \\
\text { mente o tema } \\
\text { na literatura } \\
\text { acadêmica como } \\
\text { um todo }\end{array}$ \\
\hline & $\begin{array}{l}\text { Situa a pesquisa } \\
\text { no contexto his- } \\
\text { tórico do campo } \\
\text { de estudo }\end{array}$ & $\begin{array}{l}\text { Não discute } \\
\text { a história do } \\
\text { tópico }\end{array}$ & $\begin{array}{l}\text { Alguma menção } \\
\text { à historia do } \\
\text { tema }\end{array}$ & $\begin{array}{l}\text { Examina critica- } \\
\text { mente a história } \\
\text { do tema }\end{array}$ \\
\hline & $\begin{array}{l}\text { Adquire e melho- } \\
\text { ra o vocabulário } \\
\text { sobre o assunto }\end{array}$ & $\begin{array}{l}\text { Vocabulário-cha- } \\
\text { ve não discutido }\end{array}$ & $\begin{array}{l}\text { Define o vocabu- } \\
\text { lário-chave }\end{array}$ & $\begin{array}{l}\text { Discute e resol- } \\
\text { ve ambiguidades } \\
\text { nas definições }\end{array}$ \\
\hline & $\begin{array}{l}\text { Articula variáveis } \\
\text { importantes } \\
\text { e fenômenos } \\
\text { relevantes para o } \\
\text { tema }\end{array}$ & $\begin{array}{l}\text { Não discute } \\
\text { variáveis-chave e } \\
\text { fenômenos }\end{array}$ & $\begin{array}{l}\text { Revisa as } \\
\text { relações entre } \\
\text { variáveis-chave e } \\
\text { fenômenos }\end{array}$ & $\begin{array}{l}\text { Identifica } \\
\text { ambiguidade } \\
\text { na literatura e } \\
\text { propõe novas } \\
\text { relações }\end{array}$ \\
\hline & $\begin{array}{l}\text { Sintetiza e do- } \\
\text { mina uma nova } \\
\text { perspectiva sobre } \\
\text { a literatura }\end{array}$ & $\begin{array}{l}\text { Aceita a } \\
\text { literatura pelo } \\
\text { seu valor }\end{array}$ & $\begin{array}{l}\text { Realiza algumas } \\
\text { criticas à } \\
\text { literatura }\end{array}$ & $\begin{array}{l}\text { Oferece nova } \\
\text { perspectiva }\end{array}$ \\
\hline
\end{tabular}

Lovitts apresenta, ainda, outra classificação, mais apurada, da revisão de literatura (Quadro 2, em anexo), quanto a Avaliação da revisão da literatura de uma tese, segundo níveis de qualidade, classificando-a em marcante, muito boa, aceitável e inaceitável. A Qualidade Marcante se caracteriza pela concisão, coerência, abrangência à exaustão e atualização; em relação ao tema - apresenta um pensamento crítico/ analítico, sintetiza o encontrado, faz a inter-relação com outros campos e constrói argumentos próprios para o aprimoramento do campo; em relação ao objeto de estudo - desvela o histórico e o contexto, bem como levanta problemas e limites. Uma literatura marcante também é seletiva, formuladora de categorias temáticas e leva o leitor a olhá-la de forma diferenciada. 
Quadro 2: Avaliação da revisão da literatura de uma tese segundo níveis de qualidade Fonte: Lovitts, 2007

\begin{tabular}{|c|c|c|c|}
\hline \multicolumn{4}{|c|}{ Níveis de qualidade } \\
\hline Marcante & Muito bom & Aceitável & Inaceitável \\
\hline $\begin{array}{l}\text { - Abrangente, } \\
\text { completa, coerente, } \\
\text { concisa e atualizada; } \\
\text { - Mostra o } \\
\text { pensamento crítico } \\
\text { e analítico sobre a } \\
\text { literatura; } \\
\text { - Sintetiza a literatura; } \\
\text { - Integra a literatura } \\
\text { de outros campos; } \\
\text { - Demonstra } \\
\text { compreensão da } \\
\text { história e do contexto } \\
\text { do problema; } \\
\text { - Identifica problemas } \\
\text { e limitações; } \\
\text { - É seletiva - } \\
\text { discrimina entre } \\
\text { obras com e sem } \\
\text { importância; } \\
\text { - Identifica e organiza } \\
\text { a análise em torno de } \\
\text { temas ou categorias } \\
\text { conceituais; } \\
\text { - Adiciona insights } \\
\text { próprios; } \\
\text { - Utiliza a literatura } \\
\text { para construir um } \\
\text { argumento e avançar } \\
\text { no campo; } \\
\text { - É como um bom } \\
\text { artigo de revisão; } \\
\text { - Faz o leitor olhar } \\
\text { para a literatura de } \\
\text { forma diferente }\end{array}$ & $\begin{array}{l}\text { - Abrangente, mas } \\
\text { não exaustiva; } \\
\text { - Faz uma crítica } \\
\text { precisa e acurada da } \\
\text { literatura; } \\
\text { - Mostra } \\
\text { compreensão e } \\
\text { domínio sobre } \\
\text { a maior parte da } \\
\text { literatura relevante; } \\
\text { - Seleciona literatura } \\
\text { sábia e criteriosa- } \\
\text { mente; } \\
\text { - Situa o problema } \\
\text { no contexto; } \\
\text { - Utiliza literatura } \\
\text { para construir um } \\
\text { caso para a pesquisa }\end{array}$ & $\begin{array}{l}\text { - Cobertura adequa- } \\
\text { da da literatura; } \\
\text { - Demonstra que a } \\
\text { literatura foi lida e } \\
\text { compreendida; } \\
\text { - Carece de análise } \\
\text { crítica e síntese; } \\
\text { - Não é seletiva - não } \\
\text { faz distinção entre as } \\
\text { obras mais e menos } \\
\text { relevantes; } \\
\text { - Não considera algu- } \\
\text { mas obras impor- } \\
\text { tantes; } \\
\text { - Cita algumas } \\
\text { obras que não são } \\
\text { relevantes; } \\
\text { - É uma lista indife- } \\
\text { renciada "esta pessoa } \\
\text { disse isto, esta pessoa } \\
\text { disse aquilo"; } \\
\text { - Não coloca o pro- } \\
\text { blema em contexto }\end{array}$ & $\begin{array}{l}\text { - Inadequada ou } \\
\text { incompleta; } \\
\text { - Não leu nem cita } \\
\text { fontes suficientes; } \\
\text { - Interpreta mal } \\
\text { ou não entende a } \\
\text { literatura; } \\
\text { - Não considera, } \\
\text { omite ou ignora } \\
\text { estudos importantes, } \\
\text { áreas inteiras ou } \\
\text { literatura de pessoas } \\
\text { que fizeram a mes- } \\
\text { ma coisa; } \\
\text { - Cita fontes não } \\
\text { lidas ou das quais } \\
\text { foi lido somente o } \\
\text { resumo; } \\
\text { - Cita artigos desa- } \\
\text { tualizados; } \\
\text { - Não fornece um } \\
\text { contexto para a } \\
\text { pesquisa }\end{array}$ \\
\hline
\end{tabular}

Complementando as proposições dos Quadros 1 e 2, Quivy e Campenhoudt (2005) apontam como critérios de escolha do corpus de análise: ligações com a pergunta de partida e/ou com o tema da futura produção; dimensão razoável do programa de leitura; elementos de análise e de interpretação; abordagens diversificadas do tema; e existência de tempo consagrado à reflexão pessoal e às trocas de ponto de vista. 
Além daqueles apontados acima, no Brasil, para a área da Educação, são acrescidos os seguintes critérios constitutivos do corpus de análise: a representatividade nacional e/ou internacional do veículo que publica o texto; a presença de corpo editorial reconhecido na comunidade acadêmica; e a legitimidade junto aos órgãos nacionais avaliativos.

\section{Questões da metodologia da prática do estado de conhecimento}

Uma quarta categoria temática se refere à metodologia para a construção do Estado de Conhecimento. Se a publicação em um periódico é uma forma de consagração, de reconhecimento de um autor como membro do campo acadêmicocientífico, ela supõe também um percurso anterior, de constituição de sua identidade de pesquisador. A autoria tem sido um dos maiores desafios da produção científica. Bianchetti (2004) afirma a aprendizagem da escrita e a construção da autoria como processos mediados que demandam tempo e persistência.

Sem dúvida, é neste contexto que podemos apresentar os principais passos de um seminário denominado "Construindo o estado de conhecimento de sua tese ou dissertação". De acordo com sua súmula, o seminário metodológico-instrumental busca propiciar ao discente a identificação, a análise e a produção de texto fundamentador de sua monografia de pós-graduação, com base na produção científica sobre educação, fundamentalmente no Brasil, após a promulgação da Lei de Diretrizes e Bases da Educação Nacional de 1996. A consulta bibliográfica se apoia, principalmente, em fontes nacionais, podendo se estender a obras latino-americanas e internacionais. Paralelamente, propõe a reflexão sobre a construção da produção científica como forma textual. Entre seus objetivos, destacam-se: conhecer, sistematizar e avaliar a produção científica da área da Educação na contemporaneidade; elaborar produção textual, apoiada em princípios de estado de conhecimento sobre a temática da tese ou dissertação; subsidiar a construção da dissertação e/ou tese em educação; cultivar babitus científico, visando à prática de pesquisa articulada à realidade; e compreender a produção científica na perspectiva do seu campo.

A metodologia do seminário implica em $45 \mathrm{~h}$ semestrais, interconectando aulas presenciais e atividades online, com o apoio do repositório livre Moodle (PUCRS, 2012). O discente desenvolve capacidades de aprendizagem ativa e colaborativa, na qual seu engajamento no projeto de tese ou dissertação é fundamental. Esse compromisso da disciplina com o tema da monografia motiva o aluno a se envolver. Há uma relação direta entre o mapeamento, a formulação de categorias, as análises a serem realizadas e a construção da sua monografia. $O$ aluno passa a se sentir parte de uma aprendizagem individualizada, mas com características colaborativas.

A aprendizagem ativa implica numa atitude proativa do discente, na qual duas características se tornam definidoras do sucesso: a autonomia e o disciplinamento. $\mathrm{Na}$ medida em que o discente vai construir o estado de conhecimento de sua tese ou dissertação, ele tem autonomia para buscar respostas e orientações nos materiais já produzidos e selecionados, criar categorias e refletir a partir de análises. Por outro lado, 
esta autonomia deve vir acompanhada do disciplinamento, marcado pela responsabilidade de dar conta das atividades propostas em tempo real, pela consulta aos bancos de dados selecionados, pela leitura flutuante e pelas posteriores sistematizações do material selecionado e proposições de categorias temáticas.

Neste contexto, cabe ao professor e ao aluno, a seleção do corpus de análise.

As fases metodológicas iniciais do seminário são:

- Análise de textos sobre produção científica, seus princípios, políticas e condicionantes, na perspectiva nacional e internacional;

- Identificação da temática da tese ou da dissertação, com clarificação da pergunta de partida, e das palavras-chave ligadas ao tema;

- Leitura e discussão sobre produção científica no plano teórico e no empírico (teses, dissertações, livros, congressos);

- Identificação de fontes e constituição do corpus de análise.

O corpus de análise pode ser constituído a partir de: livros - produção amadurecida; teses e dissertações - produção reconhecida junto aos órgãos de avaliação da produção nacional. Banco de todas as teses e dissertações produzidas no país com reconhecimento do governo - Capes. As monografias constituidoras deste banco são advindas de programas legitimados pela comunidade científica da área. $\mathrm{O}$ corpus de análise pode ser constituído também por textos advindos de eventos da área, que congregam o novo, o emergente e, na maioria das vezes, o pensamento da comunidade acadêmica. envolvem:

A partir da constituição do corpus da análise, fases seguintes do seminário

- Leitura flutuante do corpus de análise para a identificação dos textos;

- Construção da bibliografia anotada e da sistematizada;

- Seminários coletivos de discussão das temáticas individuais com a classe de estudantes e com os estudantes individualmente;

- Proposição de possíveis categorias, a partir da análise de conteúdo (BARDIN, 1979) ou da análise textual discursiva (MORAES, GALLIAZZI, 2006). Nesta fase, pode-se empregar softwares de análise qualitativa como Qualtrics (QUALTRICS LABS, 2012), NVivo (QSR INTERNATIONAL, 2013) ou Wordle (FEINBERG, [201-]);

- Novos seminários coletivos de discussão das temáticas individuais com a classe de estudantes, já com produção textual inicial;

- Entrevista com pesquisador, professor da área ou orientador para a busca do entendimento do encontrado;

- Redação de texto, seguindo as normas de um artigo;

- Inscrição do aluno para apresentar trabalho de construção do estado de conhecimento, se possível, em algum seminário qualificado da área da produção textual; 
- Apresentação individual final, ao grupo, em atividade de seminário.

A avaliação do seminário é contínua e inclui a participação nos seminários teóricos e a apresentação do desenrolar da construção do estado de conhecimento de cada discente e, prioritariamente, a produção textual final e sua apresentação à classe. laborativa

O Estado de conhecimento, apoiado na metodologia da aprendizagem co-

\begin{abstract}
... e em todas as suas manifestações (aprendizagem com os colegas, tutorial entre colegas, resolução de problemas de casos), correlacionam positivamente com a resolução de problemas, a retenção de conhecimento em longo prazo, o rendimento, a aplicação de conceitos, a sensibilidade aos sentimentos de outros alunos, as atitudes positivas sobre a área do assunto, o comportamento de liderança estudantil, a consciência ocupacional, a abertura dos alunos a diversidade, os ganhos em habilidades em grupo e a permanência. (CABRERA, 2010 p. 55).
\end{abstract}

\title{
Algumas considerações
}

Um dos maiores desafios enfrentados na produção científica é a autoria do texto. Inúmeras receitas são fornecidas, mas grande parte dos discentes sente-se inseguro ao construir sua tese ou dissertação. Buscando contribuir para uma produção qualificada, a partir de pesquisa durante quatro anos, elaboramos este texto que trata da produção científica, com especial atenção à construção de estado de conhecimento de monografias de cursos de pós-graduação em Educação.

Apoiamo-nos na concepção de campo científico de Bourdieu, buscando apontar os condicionantes desta produção na perspectiva de campo social com suas relações de força, lutas e estratégias, interesses e lucros. Identificamos a ciência oficial, com especial atenção aos critérios de qualidade determinados pelo estado objetivado e pelo estado incorporado.

Neste estudo de caso, que imbricou teoria e prática, identificamos quatro categorias temáticas desveladoras da construção de um Estado de Conhecimento, no Brasil, na área de educação. São elas: Políticas Estatais (gerais e disciplinares); Finalidades; Qualidade Interna; e Metodologia da Prática.

Perspectiva das Políticas Estatais - No Brasil, frente à centralização normativa e gestora governamental, as orientações da área de Educação interferem sobre a avaliação da produção científica no tocante a livros, coletâneas e periódicos. Esta importância não se associa apenas à busca por produção qualificada, mas explicita a relação direta entre a avaliação e classificação dos programas e dos pesquisadores e o seguimento, em suas práticas de produção e publicação, dos parâmetros da ciência oficial.

Perspectiva das Finalidades - O estado de conhecimento é parte integrante da tese, contribuindo, primordialmente, na fase metodológica da ruptura de pré-conceitos (QUIVY, CAMPENHOUDT, 2005), que tem, entre seus itens, leituras e ex- 
ploração inerentes à revisão de literatura. Sem dúvida, a revisão de literatura engloba não só a perspectiva de paradigmas, de consolidação do arcabouço teórico sustentador das diversas posições relativas à temática, mas engloba aquilo que foi produzido como resultado de pesquisas nos níveis nacional e internacional. Mas o estado de conhecimento traz um aprimoramento - a fase da exploração do tema, que implica, além da leitura do tema da monografia, o recurso a entrevistas com experts, sejam eles pesquisadores ou práticos, profissionais atuantes na temática fora da academia.

Perspectiva da Qualidade Interna - Adentrando na especificidade da construção da monografia, o texto tematiza parâmetros orientadores de um estado de conhecimento em educação, identificando qualidades de uma revisão de literatura (LOVITTS, 2007), as quais se sintetizam nas dimensões de abrangência e de síntese. A primeira discute os critérios de inclusão/exclusão de produções no corpus de análise. A segunda aponta as lacunas da produção, situa o problema da tese ou da dissertação no contexto geral da produção da área e, mais especificamente, no contexto histórico do campo de estudo, aprimora o vocabulário sobre o assunto, articula variáveis importantes e fenômenos relevantes para o tema e, finalmente, sintetiza e domina uma nova perspectiva sobre a literatura.

Perspectiva da Metodologia da Prática - O texto, a partir da experiência em seminários e orientações a discentes de pós-graduação, aponta uma possibilidade de construção sistemática de um estado de conhecimento na perspectiva de uma aprendizagem colaborativa.

Ao final, resta-nos a certeza da complexidade da produção científica decorrente de inúmeras inter-relações advindas da estrutura da área de conhecimento, das políticas científicas-educacionais, de órgãos gestores, da comunidade acadêmica, da própria cultura de pesquisa presente no nível institucional, da pessoa que produz, dos grupos de pesquisa e de outros fatores. Por outro lado, apresentamos possibilidades de auxílio à construção de teses ou dissertações. Uma destas possibilidades a despontar é a construção de estados de conhecimento, aqui entendidos como identificação, síntese e reflexão sobre o já produzido sobre uma temática em um determinado recorte temporal e espacial. Numa perspectiva de aprendizagem ativa e colaborativa, pela qual o sujeito assume o compromisso com a sua reflexão crítica, com a construção de seu objeto e com a inserção no campo científico.

\section{Referências}

ALBARELLO, L. et al. Práticas e métodos de investigação em ciências sociais. Lisboa: Gradiva, 2005. (Coleção Trajectos). 189 p.

BACHELARD, G. O novo espírito científico. Rio de Janeiro: Tempo Brasileiro, 1985. 363 p. BARDIN, L.Análise de Conteúdo. Lisboa: Ed. 70, 1979. 281 p.

BIANCHETTI, L. Estabelecendo interlocuções no processo de autoria: o desafio de escrever dissertações e teses. In: SEMINÁRIO DE PESQUISA EM EDUCAÇÃO - REGIÃO SUL, 5, 2004, Curitiba. Anais do V ANPEd-Sul. Curitiba: ANPEd-Sul, 2004. p. [1] - [15]. Disponível em: <http://www.portalanpedsul.com.br/admin/uploads/2004/Mesa_Redonda/ 
Mesa_Redonda/08_12_39_ESTABELECENDO_INTERLOCUCOES_NO_PROCESSO_DE_AUTORIA_O_DESAFIO.pdf $>$. Acesso em: 17 fev. 2014.

BOURDIEU, P. O campo científico. In: ORTIZ, R. (Org.). Pierre Bourdieu: sociologia. São Paulo: Ática, 1983. p. 122-155.

CABRERA, A., LA NASA. Práticas na sala de aula: A aprendizagem de 10 lições. In: AUDY,J, MOROSINI, M. C. Inovação e qualidade da Educação Superior. Porto Alegre: EdiPUCRS/ CAPES/CNPq/INEP. 2008. Disponível em: http://www.pucrs.br/edipucrs/inovacaoequalidade.pdf. Acesso em: 12 fev. 2014. p. 44-74.

CAMPENHOUDT, L. V. Introdução à análise dos fenómenos sociais. Lisboa: Gradiva, 2003. $275 \mathrm{p}$.

COORDENAÇÃO DE APERFEIÇOAMENTO DE PESSOAL DE NÍVEL SUPERIOR (CAPES). Diretoria de Avaliação (DAV). Documento de área 2013. (Educação). Disponível em: <http://www.capes.gov.br/images/stories/download/avaliacaotrienal/Docs_de_area/Educação_doc_area_e_comissão_21out.pdf>.Acesso em: 26 jan. 2014.

FEINBERG, J. Wordle: beautiful word clouds. [201-]. Disponívelem: <http://www.wordle. net/>. Acesso em: 17 fev. 2014.

INTERNATIONAL ISBN AGENCY. Manual do Usuário ISBN: edição internacional. 6. ed. London: International ISBN Agency, 2011.

ISSN INTERNATIONAL CENTRE. ISSN Manual. Paris: ISSN International Centre, 2012.

JARVEY, P.; USHER, A; MCELROY, L. Making Research Count: Analyzing Canadian Academic Publishing Cultures. Toronto: Higher Education Strategy Associates, 2012.29 p.

LOVITTS, B. E. Making the implicit explicit: creating performance expectations for the dissertation. Virginia: Stylus, 2007. 248 p.

LÜDKE, M., ANDRÉ, M. Pesquisa em educação: abordagens qualitativas. São Paulo: EPU, 1986. $70 \mathrm{p}$.

MORAES, R.; GALLIAZZI, M. C. Análise textual discursiva: processo reconstrutivo de múltiplas faces. Ciência \& Educação, Bauru, v. 12, n. 1, p. 117-128, 2006.

MOROSINI, M. C. Qualidade e Pesquisa em Educação Superior: algumas tendências. In: BULIN, E. M. M. P.; BERBEL, N. A. N. (Orgs.). Pesquisa em Educação: inquietações e desafios. Londrina: UEL, 2012. 487 - 412

PONTIFÍCIA UNIVERSIDADE CATÓLICA DO RIO GRANDE DO SUL - PUCRS. Pró-Reitoria de Extensão. Coordenadoria de Educação a Distância. Ambiente Virtual de Aprendizagem Moodle - Versão 2.2. Manual do Professor. Porto Alegre: PUCRS/CEAD, 2012. 393 p.

QSR INTERNATIONAL. An overview of NVivo: software to support qualitative and mixed methods research. 2013. Disponível em: <http://download.qsrinternational.com/Resource/ NVivo10/nvivo10-overview.pdf >. Acesso em: 17 fev. 2014.

QUALTRICS LABS. Qualtrics Survey Software: handbook for research professionals. Provo: QualtricsLabs, 2012.

QUIVY, R.; CAMPENHOUDT, L. V. Manual de Investigação em Ciências Sociais. 4. ed. Lisboa: Gradiva, 2005. (Coleção Trajectos). 275 p.

STOLEROFF, A.; PATRÍCIO, M.T. A prática científica. In: JESUÍNO, J. C. (Org.). A comunidade cientifica portuguesa nos finais do século $\mathrm{XX}$ : comportamentos, atitudes e expectativas. Oeiras: Celta, 1995. p. 13-32. 


\section{Notas}

${ }^{1}$ International Standard Serial Number (ISSN), ou Número Internacional Normalizado para Publicações Seriadas, é um código de oito dígitos usado para identificar jornais, revistas e periódicos, com editoração contínua, título constante e responsabilidade editorial bem definida, em meio impresso e digital. (ISSN International Centre, 2012).

${ }^{2}$ International Standard Book Number System (ISBN), ou Número Padrão Internacional de Livro,é um código de 13 dígitos que serve como identificador internacional único para publicações monográficas (International ISBN Agency, 2011).

${ }^{3}$ Nos Estados Unidos, dissertation se refere à monografia de conclusão de curso de doutorado.

* Professora Doutora da Pontifícia Universidade Católica do Rio Grande do Sul, Porto Alegre, Rio Grande do Sul, Brasil

\section{Correspondência}

Marilia Costa Morosini - Pontifícia Universidade Católica do Rio Grande do Sul, Programa de Pós-Graduação em Educação. Av. Ipiranga, 6681. CEP: 90619900, Porto Alegre, Rio Grande do Sul, Brasil.

E-mail: mariliamorosini@hotmail.com

Recebido em 15 de outubro de 2014

Aprovado em 20 de novembro de 2014 